\title{
Penetration and Absorption of Tacrolimus (FK506) Ointment in the Skin After a Single Dermal Application to the Rat
}

\author{
Akio Kawamura, Toshifumi Shiraga, Kouji Takeshita, Yoshinori Teramura, \\ Masato Terakawa, Akira Kagayama, Shinichi Ninomiya* and Yoshio Esumi*
}

Biopharmaceutical and Pharmacokinetic Research Laboratories, Fujisawa Pharmaceutical Co., Ltd., Osaka; *Tokai Research Laboratories, Daiichi Pure Chemicals Co., Ltd., Ibaraki

\begin{abstract}
Summary: The penetration and absorption of tacrolimus (FK506) in the skin of rat after a single topical application of ${ }^{14} \mathrm{C}$-labeled $\mathrm{FK} 506\left({ }^{14} \mathrm{C}-\mathrm{FK} 506\right)$ ointment under occlusive dressing was studied by semimicroautoradiography of the skin and by counting radioactivity in the sliced sections of the skin. Stability of FK506 in the skin was investigated in vivo and in vitro.

1. The distribution of the radioactivity of ${ }^{14} \mathrm{C}-\mathrm{FK} 506$ in rat skin was observed by semi-microautoradiography after a single dermal application of the ointment. In the intact skin, radioactivity of the ointment was mainly distributed in the stratum corneum of the epidermis during application for 24 hours. In the damaged skin, radioactivity was observed in the epidermis and dermis after application for 2 hours, and was evenly distributed in the dermis and subcutaneous connective tissues after application for 8 hours. Radioactivity was detected in the hair follicles of both the intact and damaged skin, but that was negligible in the sebaceous gland of the intact skin or was less than in the follicles of the damaged skin.

2. After a single dermal application of ${ }^{14} \mathrm{C}-\mathrm{FK} 506$ ointment to rats, the penetration of FK506 was investigated by counting radioactivity in the sliced section of skin. In the intact skin, maximal radioactivity was observed in the section of the epidermis throughout the application period for 24 hours. In the damaged skin, maximal radioactivity was detected in the dermis after application for 2 hours, and radioactivity in the sections was decreased thereafter and only a small amount of radioactivity was observed after application for 24 hours.

3. After application of ${ }^{14} \mathrm{C}-\mathrm{FK} 506$ ointment for 24 hours, levels of radioactivity were compared with those of FK506 in the skin, and the unchanged FK506 accounted for about 90\% of radioactivity detected.

4. The oxidative metabolism of FK506 was studied in the skin and liver microsomes. Formation of the in vitro major metabolite, the $13-\mathrm{O}$-demethylated metabolite, in the skin microsomes was several-fold less intensive than in the liver microsomes.
\end{abstract}

Key words: Tacrolimus, FK506, Ointment, Penetration, Absorption, Rat skin

\section{Introduction}

Tacrolimus (FK506) is a 23-membered macrolide antibiotic, produced by Streptomyces tsukubaensis. FK506 exhibited a very potent immunosuppressive action and has been marketed as an immunosuppressant for the prevention and control of rejection in organ transplantation. ${ }^{1)}$ In addition to being an immunosuppressor in solid organ transplantation, FK506 has shown immunosuppressive effect in a variety of autoimmune diseases. Its activity in these disorders make FK506 a prime candidate for atopic dermatitis. Clinical trials of FK506 ointment are in progress for the treatment of atopic dermatitis. ${ }^{2)}$

The rodents were used for the toxicological and pharmacological studies during the development of FK506.
We evaluated the systemic properties about absorption, distribution and excretion after topical application of FK506 ointment to rat. ${ }^{3,4)} \mathrm{A}$ lot of information of the basic systemic properties after intravenous and oral administration to rat had been accumulated for the development of Prograf ${ }^{\oplus, 5,6)}$ and rats are suitable animals for the further evaluation of FK506 ointment. For the development of ointment formulation of a drug, information about penetration of the drug into the skin is essential. In this study, we reported the penetration and absorption of FK506 in the skin after a single dermal application of ${ }^{14} \mathrm{C}-\mathrm{FK} 506$ ointment to rat.

\section{Materials and Methods}

\section{Materials}

FK506, ${ }^{14} \mathrm{C}$-labeled FK506 $\left({ }^{14} \mathrm{C}-\mathrm{FK} 506\right),{ }^{14} \mathrm{C}-\mathrm{FK} 506$ 
ointment, the 13-O-demethylated metabolite $(\mathrm{M}-\mathrm{I})$, the 31-O-demethylated metabolite (M-II), the $15-0-$ demethylated metabolite (M-III), and the 12-hydroxylated metabolite (M-IV) were obtained as described previously. ${ }^{7)}$ Specific activity of ${ }^{14} \mathrm{C}-\mathrm{FK} 506$ was 574 $\mathrm{kBq} / \mathrm{mg}$ or more and its radiochemical purity was more than $97 \%$ by thin layer chromatography. $\beta_{-}^{-}$ Nicotinamide adenine dinucleotide phosphate (NADP), glucose-6-phosphate (G-6-P), and glucose 6 -phosphate dehydrogenase $(\mathrm{G} 6-\mathrm{P} \mathrm{DH})$ were purchased from Sigma Chemical Co. Testosterone was obtained from Nakarai Tesque and used after purification by reverse phase high performance liquid chromatography (HPLC). Standards of testosterone metabolites were purchased from Steraloid. 7-Ethoxycoumarin and hydroxycoumarin were obtained from Nakarai Tesque.

\section{Animals and Treatment}

Male Sprague-Dawley strain rats (7-8 weeks old) were purchased from Clea Japan Inc. Animals were used without fasting.

On the day before dermal application, rats were anesthetized with diethyl ether and the dorsal hair was removed by clipping with electric clippers and by shaving with an electronic shaver. The damaged skin was prepared by tape-stripping ten times with adhesive tape.

\section{Semi-Microautoradiography}

Rats were anesthetized with diethyl ether and $0.5 \%$ ${ }^{14} \mathrm{C}-\mathrm{FK} 506$ ointment $(574 \mathrm{kBq} / \mathrm{mg}$ FK506) was applied on the dorsal skin $(2 \times 4 \mathrm{~cm} / 250 \mathrm{~g}$ rat $)$ with a stainless steel spatula at a dose level of $0.5 \mathrm{mg}$ FK506/100 mg ointment/kg rat. The applied site was covered with a vinyl sheet and the animal body was wrapped with an elastic bandage to prevent removal of the sheet. The maximal period of application was 24 hours. Animals were killed by exsanguination under anesthesia with diethyl ether at 2,8 or 24 hours after the start of application. The remaining ointment on the application site was removed by sweeping five times with individual cottons wet with slightly hot water, and the swept skin was dissected. The dissected skin was embedded in embedding material (O.C.T. Compound, Tissue-Tek), frozen in liquid propane cooled with liquid nitrogen, and cut in $5 \mu \mathrm{m}$ sections with a cryo-stat (CM3000, Leica). The sections were attached to a microscopic slide glass which was previously coated with emulsifier (NR-M2, Konica), and exposed for 63 days at around $-80^{\circ} \mathrm{C}$ in a black box. After the exposure, the specimens were fixed with $10 \%$ formalin, washed with water, and developed with Konicadol (Konica) followed by stopping, fixing and washing the development. The samples were dried, stained with hematoxylin and eosin stain, spread with Entelanew (E. Merck), and observed with a microscope.

\section{Penetration Study}

Rats were anesthetized with diethyl ether and $0.1 \%$ ${ }^{14} \mathrm{C}-\mathrm{FK} 506$ ointment $(643 \mathrm{kBq} / \mathrm{mg}$ FK506) was applied on the dorsal skin with a stainless steel spatula. The damaged skin was prepared on half of the clipped skin as described above and the ointment was applied to an equal area of the damaged and intact skin $(1.5 \times 3 \mathrm{~cm}$, each) of the same animal at a dose level of $0.045 \mathrm{mg}$ FK506/45 mg ointment/each site. After application, the site applied was covered with a vinyl sheet and the animal body was wrapped with an elastic bandage to prevent removal of the sheet. Animals were killed after application for 2,8 or 24 hours by exsanguination under anesthesia with diethyl ether. The remaining ointment at the application site was removed by sweeping five times with individual cottons wet with slightly hot water, the swept skin was dissected, and the damaged and intact skin was separated by cutting. Each skin was prepared at about $2 \mathrm{~mm}$ thickness and frozen. The frozen skin was punched and the columnar skin (base, 1 $\mathrm{cm}^{2}$; and height, $2 \mathrm{~mm}$ ) was prepared. The columnar skin was embedded in embedding material O.C.T. Compound, frozen as described above, and cut in $20 \mu \mathrm{m} \mathrm{sec}-$ tions from the surface of the skin. Each sliced section was mixed with $10 \mathrm{~mL}$ of Econofluor after dissolving with $0.2 \mathrm{~mL}$ of Soluene 350. Radioactivity in the treated sections was counted as described previously.7)

The rest of the punched sample was embedded, frozen, and cut in $10 \mu \mathrm{m}$ sections, attached to the slide glass, dried, and stained with hematoxylin and eosin stain. Distribution of the epidermis, dermis, and other skin constituents was observed with a microscope.

\section{Analysis of Radioactivity and FK506 in Rat Skin}

Rats were anesthetized with diethyl ether and $0.5 \%$ ${ }^{14} \mathrm{C}-\mathrm{FK} 506$ ointment $(574 \mathrm{kBq} / \mathrm{mg}$ FK506) was applied to the dorsal skin $(2 \times 4 \mathrm{~cm} / 250 \mathrm{~g}$ rat $)$ with a stainless steel spatula at a dose level of $1.6 \mathrm{mg}$ FK506/320 mg ointment $/ \mathrm{kg}$ rat. After application, the site applied was covered with a vinyl sheet and the animal body was wrapped with an elastic bandage to prevent removal of the sheet. Animals were killed after 24 hours application and $10 \%(\mathrm{w} / \mathrm{v})$ homogenates of the dissected skin were prepared in $0.1 \mathrm{~N} \mathrm{HCl} /$ ethanol $(1 / 1, \mathrm{v} / \mathrm{v})$. FK506 in the homogenates was assayed as described previously, ${ }^{7)}$ after extraction to a mixture of $\mathrm{n}$-hexane/isoamyl alcohol $(40 / 1, \mathrm{v} / \mathrm{v})$. For measurement of radioactivity, the homogenates $(100 \mu \mathrm{L})$ were dissolved in $1 \mathrm{~mL}$ of Soluene 350 and mixed with $10 \mathrm{~mL}$ of Hionicfluor, and radioactivity was counted as described previously.7)

\section{Metabolism of FK506, Testosterone and 7-Ethox- ycoumarin In vitro}

Microsomes of the skin and liver of rats were prepared as follows. After removing the dorsal hair by clipping, rats were killed by decapitation. The dorsal skin was dissected and homogenized with 3.5 volume $(\mathrm{v} / \mathrm{w})$ 
(A)

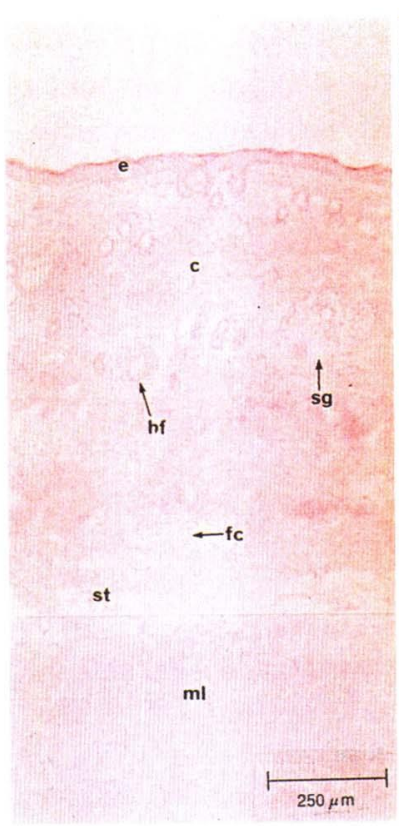

bright field

(C)

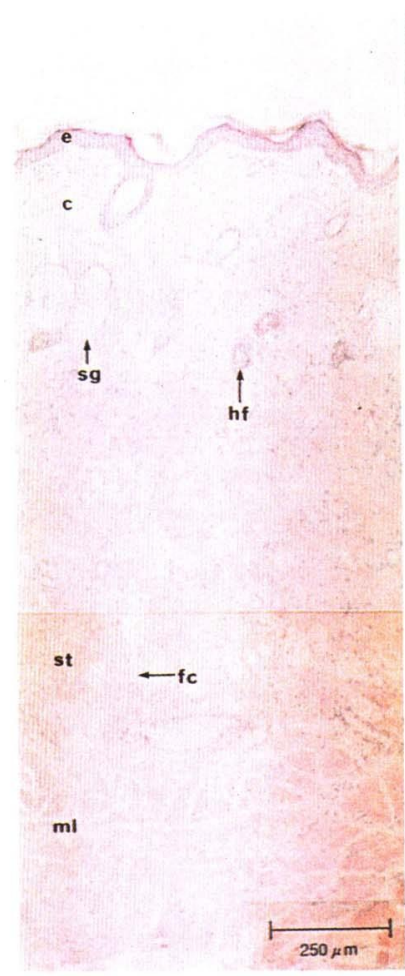

bright field
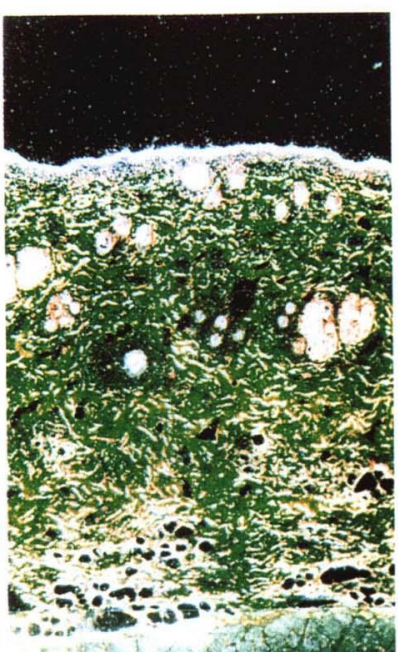

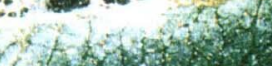

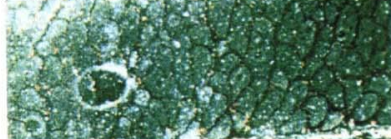

dark field
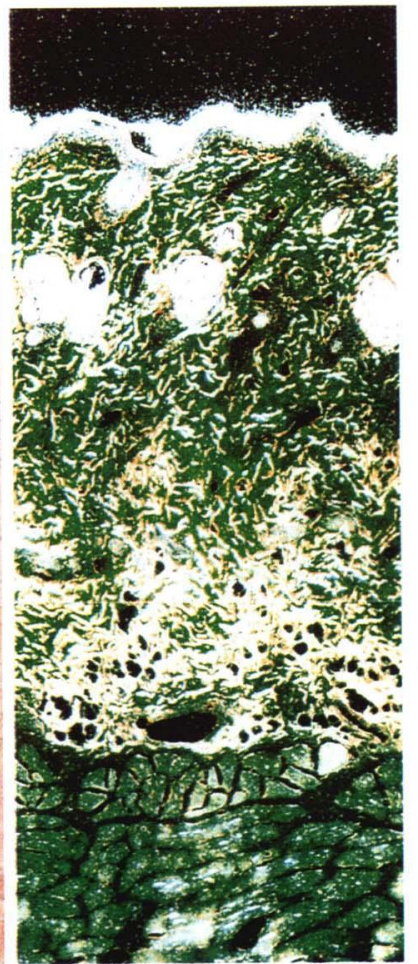

dark field

(B)

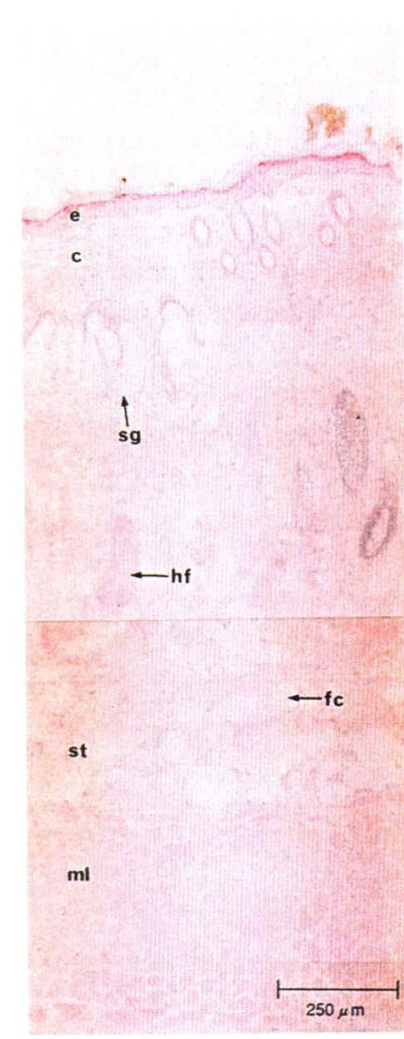

bright field

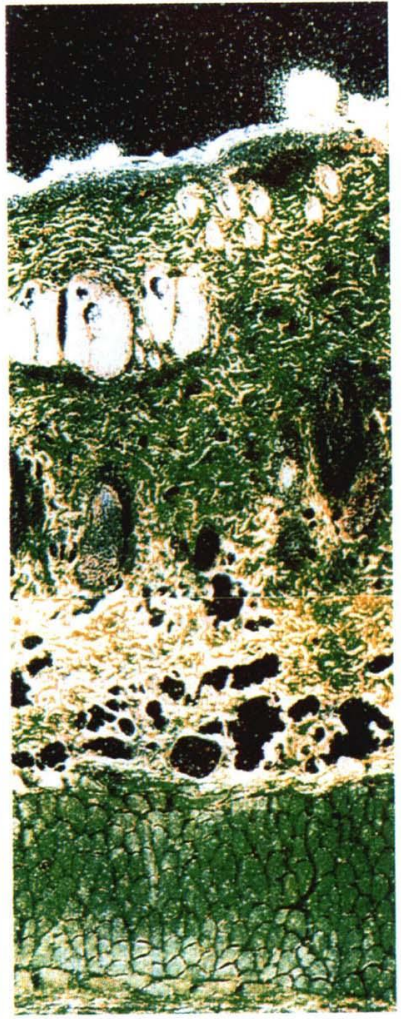

dark field

Fig. 1 Semi-microautoradiograms of the intact skin after a single dorsal application of ${ }^{14} \mathrm{C}-\mathrm{FK} 506$ ointment to rat Distribution of radioactivity was investigated after application to ${ }^{14} \mathrm{C}-\mathrm{FK} 506$ ointment for (A) 2, (B) 8, and (C) 24 hours. Dermal sites of the skin are designated as follows: c, corium; e, epidermis; fc, fat cells; hf, hair follicle; ml, muscular layer; sg, sebaceous gland; and st, subcutaneous tissue. 
of $1.15 \% \mathrm{KCl}$ solution (containing $1 \mathrm{mM}$ EDTA and $0.1 \mathrm{mM}$ dithiothreitol) with Polytron homogenizer under ice cold condition. Skin microsomes were prepared by differential centrifugation and pellets washed at $105000 \mathrm{~g}$ were homogenized in $100 \mathrm{mM}(\mathrm{pH} \mathrm{7.4)} \mathrm{K}$ phosphate buffer (containing 20\% glycerol, $1 \mathrm{mM}$ EDTA and $1 \mathrm{mM}$ dithiothreitol). Hepatic microsomes were prepared as described previously. ${ }^{8)}$ Reaction media contained $100 \mathrm{mM}$ (pH 7.4) K-phosphate buffer, NADPH generating system $(0.5 \mathrm{mM}$ NADP, $5 \mathrm{mM} \mathrm{G}$ 6-P, $1 \mathrm{U} / \mathrm{mL} \mathrm{G}-6-\mathrm{P} \mathrm{DH}$ and $5 \mathrm{mM} \mathrm{MgCl} 2$ ), microsomal suspension, and substrate. Concentrations of ${ }^{14} \mathrm{C}^{-}$ FK506, and testosterone and 7-ethoxycoumarin were $10 \mu \mathrm{M}$, and $500 \mu \mathrm{M}$, respectively. Metabolite formation of ${ }^{14} \mathrm{C}-\mathrm{FK} 506$, testosterone and 7 -ethoxycoumarin was determined as described previously. ${ }^{7,9)}$ Microsomal protein was measured by the method of Lowry et al.. ${ }^{10)}$

\section{Results}

\section{Semi-Microautoradiography}

The penetration of radioactivity in $0.5 \%{ }^{14} \mathrm{C}-\mathrm{FK} 506$ ointment was studied in the intact and damaged skin after a single dermal application to rats under occlusive dressing. After application on the intact skin for 2 hours (Fig. 1), silver particles which denote radioactivity were observed most abundantly in the epidermis, and especially in the stratum corneum. The particles were located in the upper layer of the dermis similar to or slightly lower to the radioactive level of the epidermis but were located at the back ground level in the lower layer. No particles were observed in the subcutaneous tissue, muscle layer, sebaceous gland and hair follicles. After application for 8 hours, the particles in the epidermis except in the stratum corneum were fewer than those in the epidermis after application for 2 hours, more particles were observed in the dermis and subcutaneous tissue after application for 8 hours than for 2 hours. The particles were detected in the hair follicles but not in the muscle layer, sebaceous gland and fat cells. After application for 24 hours, the particles were observed abundantly in the stratum corneum but not in the other sites.

In the damaged skin to which ${ }^{14} \mathrm{C}-\mathrm{FK} 506$ ointment
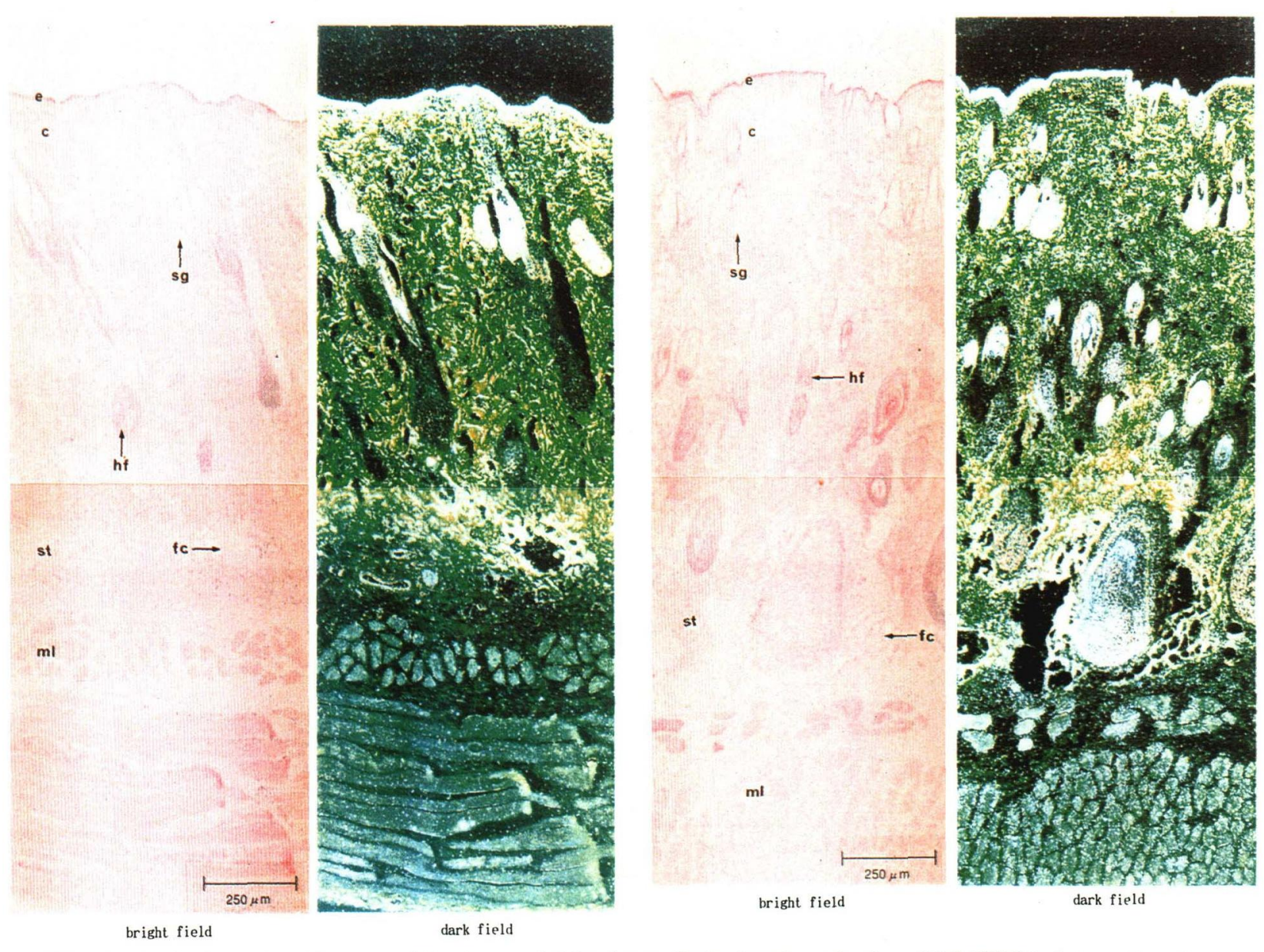

Fig. 2 Semi-microautoradiograms of the damaged skin after a single dorsal application of ${ }^{14} \mathrm{C}-\mathrm{FK} 506$ ointment to rat Distribution of radioactivity was investigated after application to ${ }^{14} \mathrm{C}-\mathrm{FK} 506$ ointment for (A) 2, (B) 8, and (C) 24 hours. The sites of the skin are designated as in the legend of Fig. 1. 
was applied for 2 hours (Fig. 2), sliver particles were observed in the epidermis and dermis, and the levels and gradient of the particles were higher than those in the intact skin with the same application period. The particles in the subcutaneous tissue and muscle layer were slightly higher than those of background level. These were detected in the hair follicles of the dermis but not in the sebaceous gland. After application for 8 hours, the particles were generally higher in the damaged skin than those of the intact skin. The particles were evenly distributed in the dermis and subcutaneous connective tissue, and the particles in the hair follicles were more abundant than those in the sebaceous gland and fat cells. After application for 24 hours, the particles detected were generally few in the damaged skin but were slightly more abundant in the regenerated stratum corneum.

\section{Penetration Study}

After a single dermal application of $0.1 \%{ }^{14} \mathrm{C}-\mathrm{FK} 506$ ointment under occlusive condition, radioactivity in the sliced sections of the intact and damaged skin was deter-

(C)

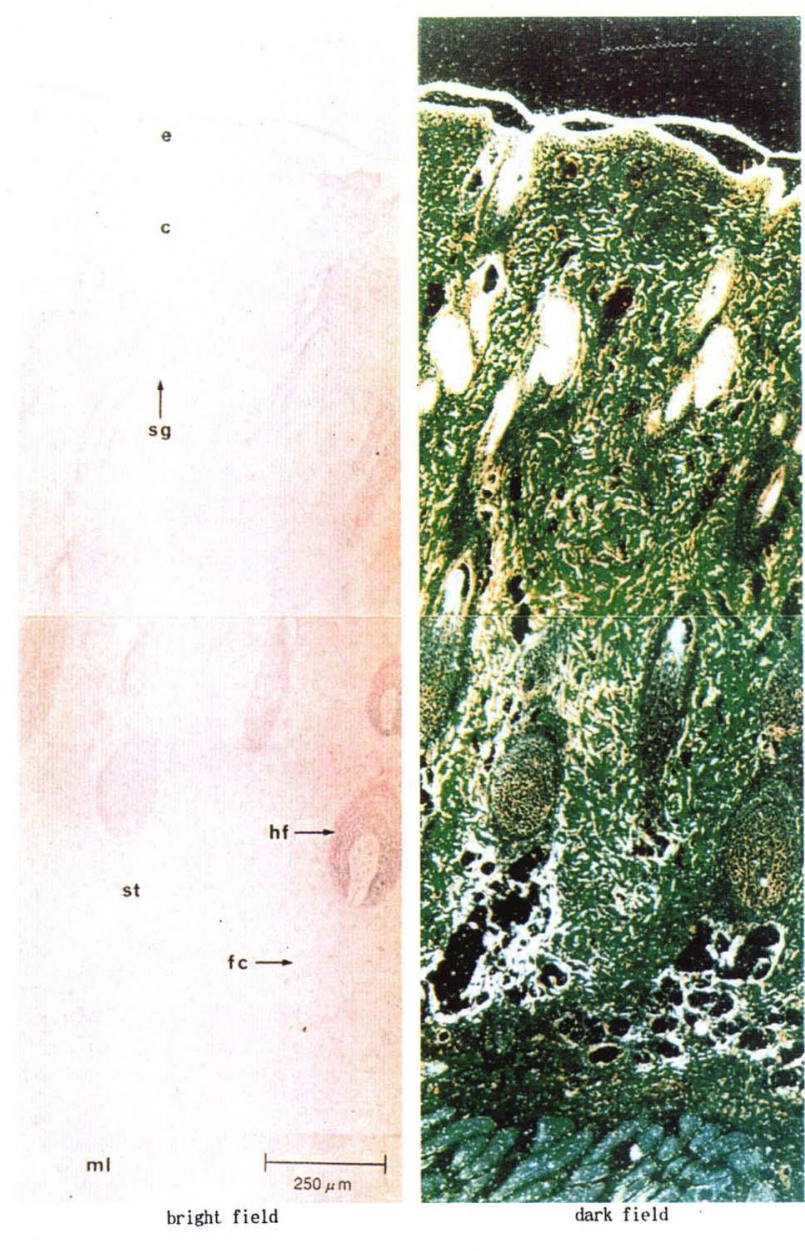

Intact skin

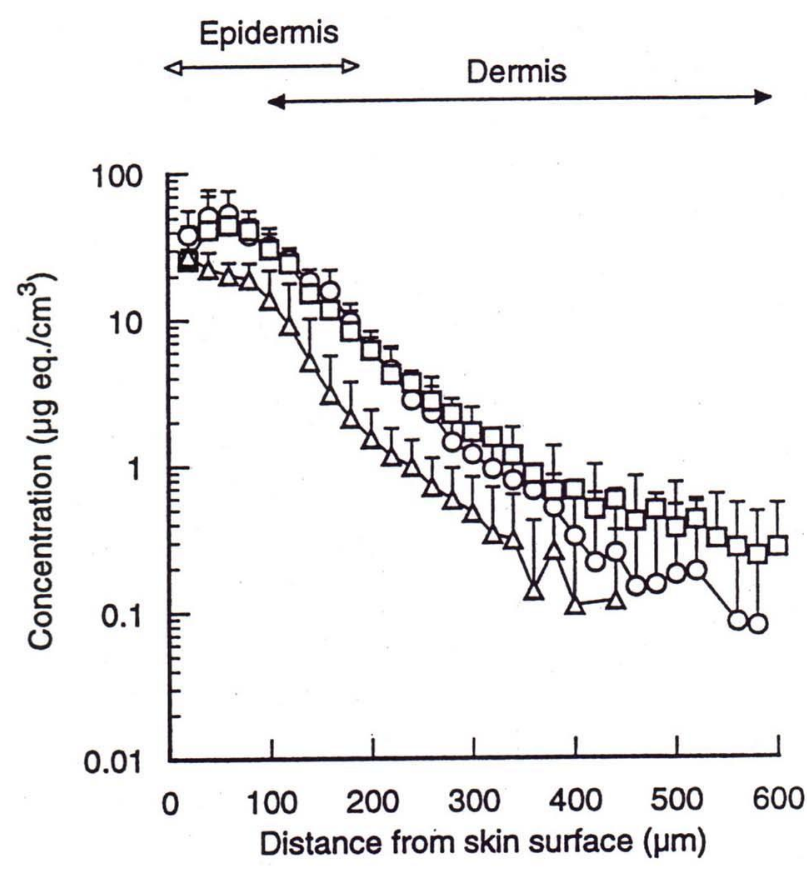

Fig. 3 Distribution of radioactivity in the sections of intact skin after a single dorsal application of ${ }^{14} \mathrm{C}-\mathrm{FK} 506$ ointment to rat

Distribution of radioactivity in skin slices was estimated after application to ${ }^{14} \mathrm{C}-\mathrm{FK} 506$ ointment for (○) 2, ( $\square$ ) 8, and $(\triangle) 24$ hours. Each point represents mean + S.E.

mined. In the intact skin (Fig. 3), the distribution of radioactivity in the samples collected after application for 2 and 8 hours was almost the same and peaked at 60 $\mu \mathrm{m}$ depth from the skin surface with a concentration of about $50 \mu \mathrm{g}$ eq. $/ \mathrm{cm}^{3}$ skin. After application for 24 hours, the distribution of radioactivity was similar to that applied for 2 and 8 hours. In the respective section at the same depth, the level of radioactivity in the sections after application for 24 hours was about half or one third of the level of the sections applied for 2 and 8 hours. The distribution of radioactivity in the sections at a range of 0 to $80 \mu \mathrm{m}$ was almost flat and in the sections deeper than $80 \mu \mathrm{m}$ gradually decreased. In the damaged skin (Fig. 4), maximal radioactivity was detected in the section at around $140 \mu \mathrm{m}$ depth with a concentration of 20 $\mu \mathrm{g}$ eq. $/ \mathrm{cm}^{3}$ skin after application for 2 and 8 hours. The distribution of radioactivity was flatter than that of the intact skin at respective depth, and also the range of flat level was wider. Radioactivity in the sections after 2 hours application was higher than that after application for 8 hours, and only a small amount of radioactivity was observed in the sections after application for 24 hours.

\section{Concentrations of Radioactivity and FK506 in Rat Skin}

After a single dermal application of $0.5 \%{ }^{14} \mathrm{C}-\mathrm{FK} 506$ 


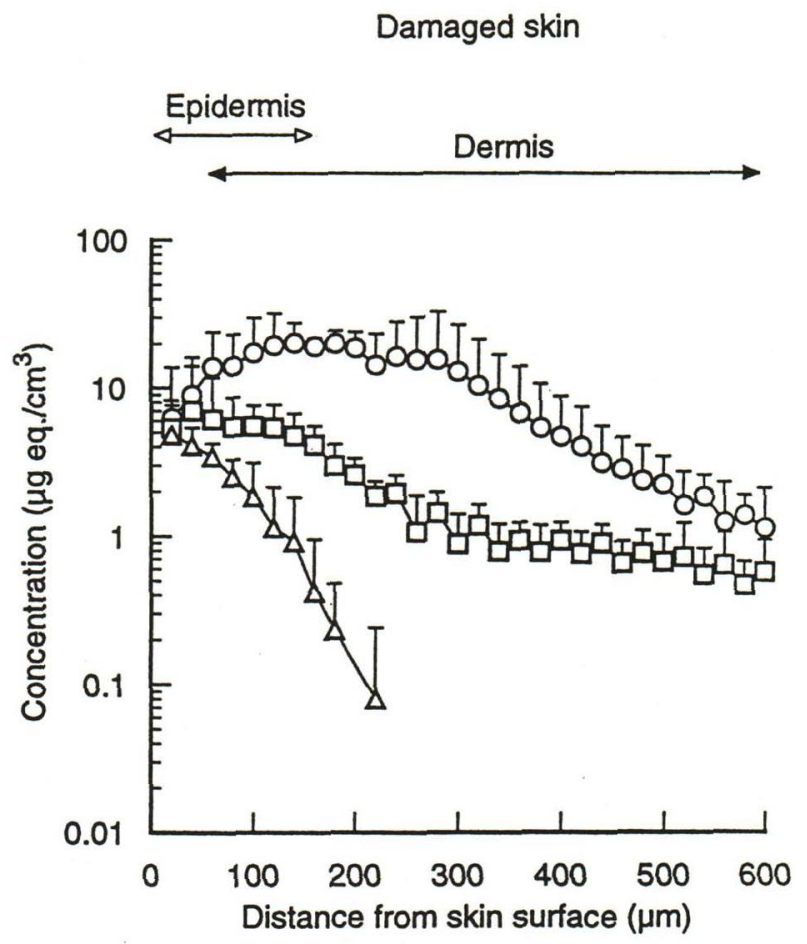

Fig. 4 Distribution of radioactivity in the sections of damaged skin after a single dorsal application of ${ }^{14} \mathrm{C}-$ FK506 ointment to rat

Distribution of radioactivity in skin slices was estimated after application to ${ }^{14} \mathrm{C}-\mathrm{FK} 506$ formulation for (○) 2, $(\square)$ 8, and $(\triangle) 24$ hours. Each point represents mean + S.E.

Table I Concentration of radioactivity and FK506 in rat skin at 24 hours after single dermal application of $0.5 \%{ }^{14} \mathrm{C}-\mathrm{FK} 506$ ointment

\begin{tabular}{ccccc}
\hline \multirow{2}{*}{$\begin{array}{c}\text { Rat } \\
\text { number }\end{array}$} & Radioactivity & & FK506 & Ratio \\
(ng eq./g) & & (ng/g) & \\
\hline 1 & 5453.5 & & 5166.6 & 0.9474 \\
2 & 3288.0 & & 2800.0 & 0.8516 \\
3 & 3915.2 & & 3519.6 & 0.8990 \\
\hline Mean & 4218.9 & 3828.7 & 0.8993 \\
S.D. & 1114.2 & 1213.2 & 0.0277 \\
C.V. $(\%)^{\text {a) }}$ & 26.4 & 31.7 & 3.1 \\
\hline
\end{tabular}

a) : C.V. $(\%)=$ Mean/S.D. $\times 100$

ointment to rat intact skin under occlusive dressing, levels of radioactivity and FK506 in the skin were determined (Table I). After application of the ointment for 24 hours, mean concentrations of radioactivity and FK506 were about $4200 \mathrm{ng}$ eq. $/ \mathrm{g}$ and $3800 \mathrm{ng} / \mathrm{g}$, respectively, and the unchanged FK506 accounted for about $90 \%$ of radioactivity in the skin. Although there were wide individual differences in concentrations of radioactivity and FK506, the ratio of FK506 to radioactivity was quite constant.
Table II Oxidative metabolism of FK506, testosterone and 7-ethoxycoumarin by skin and liver microsomes of rats

\begin{tabular}{llcr}
\hline \multirow{2}{*}{ Substrate } & \multicolumn{1}{c}{ Reaction } & \multicolumn{2}{c}{ Activity } \\
\cline { 3 - 4 } & & \multicolumn{2}{c}{$\left.\begin{array}{c}\text { pmol/min/mg } \\
\text { protein }\end{array}\right)$} \\
\cline { 3 - 4 } & & Skin & Liver \\
\hline FK506 & M-I formation & 0.071 & 194 \\
\hline Testosterone & $2 \alpha$-Hydroxylation & n.d. & 1700 \\
& $2 \beta$-Hydroxylation & n.d. & 250 \\
& $6 \beta$-Hydroxylation & 1.3 & 2330 \\
& $7 \alpha$-Hydroxylation & n.d. & 150 \\
& $16 \alpha$-Hydroxylation & n.d. & 2020 \\
& $16 \beta$-Hydroxylation & n.d. & 30 \\
\hline 7-Ethoxycoumarin & 0-Deethylation & 0.31 & 1030 \\
\hline
\end{tabular}

Values represent mean of duplicate experiments. n.d. : not detected.

\section{Oxidative Metabolism of FK506 by Microsomes}

Oxidative metabolism of FK506, testosterone and 7ethoxycoumarin was studied in skin and liver microsomes of rats (Table II). Formation rate of M-I, the in vitro major metabolite of FK506, was 0.071 and 194 $\mathrm{pmol} / \mathrm{min} / \mathrm{mg}$ protein in the skin and liver microsomes, respectively. Although $2 \alpha^{-}, 2 \beta^{-}, 6 \beta^{-}, 7 \alpha^{-}, 16 \alpha^{-}$and $16 \beta$-hydroxylating activities of testosterone were detected in the hepatic microsomes, only $6 \beta$-hydroxylation activity was detected in the skin microsomes. Oxidative metabolism of FK506, testosterone and 7-ethoxycoumarin was much less in the skin microsomes than that by the hepatic microsomes.

\section{Discussion}

The distribution and penetration of radioactivity in the skin was studied after a single dermal application of ${ }^{14} \mathrm{C}-\mathrm{FK} 506$ ointment to rats. About $90 \%$ of radioactivity was accounted for by the unchanged FK506 in the skin collected after application of the ointment for 24 hours. Oxidative metabolism of FK506 by skin microsomes was very low when compared to that by liver microsomes. These results indicate that the distribution and penetration of radioactivity observed in this study shows that the unchanged FK506 in rat skin is stable for at least 24 hours.

The transdermal absorption route of drugs is classified into two pathways; one is the transepidermal route through the stratum corneum and the other is the transappendageal route through the pilosebaceous unit or ecrine gland. ${ }^{11)}$ The stratum corneum functions as a barrier of drug absorption in the transepidermal route, and the absorption is extensively enhanced under the condition without the stratum corneum, such as the damaged skin prepared by removing the stratum corneum with adhesive tape. After application of ${ }^{14} \mathrm{C}-\mathrm{FK} 506$ ointment to 
the intact skin, FK506 was mainly distributed in the stratum corneum of the epidermis during application of the ointment for 24 hours. In the damaged skin, FK506 was observed in the epidermis and dermis after application for 2 hours, and was evenly distributed in the dermis and subcutaneous connective tissues after application for 8 hours. Radioactivity was detected in the hair follicles of the intact and damaged skin, but that in the sebaceous gland was negligible in the intact skin or less than in the follicles of the damaged skin. These results support our previous conclusions that the stratum corneum of rat skin acts as a barrier against the absorption of FK506 in the ointment, and that FK506 in the ointment is absorbed through the transepidermal route of the rat.3,4)

After a single dermal application of ${ }^{14} \mathrm{C}-\mathrm{FK} 506$ ointment to rats, distribution of radioactivity in the sliced sections differed between the intact and damaged skin. The distribution was steeper in the intact skin with a peak distribution at the epidermis, and radioactivity was more evenly distributed in the damaged skin after application for 2 and 8 hours. FK506 was mainly distributed in the stratum corneum from the results of semi-microautoradiography of the intact skin. These results indicate that the high distribution of FK506 in the stratum corneum affects on the radioactivity in the outer few sliced sections of the intact skin. As reported previously, ${ }^{3)}$ excretion of radioactivity in the urine and feces was respectively 0.4 and $4.2 \%$ of dose after application to the intact skin and 2.4 and $53.6 \%$ to the damaged skin. Radioactivity remaining in the ointment after application for 24 hours was 69.6 and $38.3 \%$, respectively, on the intact and damaged skin, and radioactivity detected at the application site was 22.6 and $4.7 \%$ in the intact and damaged skin. Although the level of radioactivity in the sliced sections of the damaged skin was lower than that of the intact skin, the large bioavailability was observed in the damaged skin. The results of the present and previous study indicate that radioactivity is absorbed more rapidly through the damaged skin than the intact skin, and absorbed radioactivity is excreted mainly in the feces as observed in the result after intravenous injection of ${ }^{14} \mathrm{C}-\mathrm{FK} 506 .{ }^{6}$ )

Microsomes from rat skin catalyzed $\mathrm{O}$-deethylation of 7-ethoxycoumarin and hydroxylation of testosterone but their specific activities were much lower than those of liver microsomes as previously reported. ${ }^{12)}$ In this study, only $6 \beta$-hydroxylation of testosterone was detected by skin microsomes but no hydroxylation at other positions. The results suggest that cytochrome P450 3A (CYP3A) is present in the rat skin but its activity and/ or content is very low. CYP3A was reported to catalyze oxidative metabolism of FK506 in rat and human. ${ }^{13)}$ Contribution of microsomes or CYP3A in rat skin to the metabolism of FK506 during the penetration of FK506 through the skin should be very little or negligible, considering the very low specific activity of FK506 metabolism by rat skin microsomes. This suggestion is supported by the fact that unchanged FK506 occupied a major portion of radioactivity in the skin after a single dermal application of ${ }^{14} \mathrm{C}-\mathrm{FK} 506$ formulation.

\section{References}

1) Peters D. H., Fitton A., Plosker G. L. and Faulde D.: Tacrolimus. A review of its pharmacology, and therapeutic potential in hepatic and renal transplantation. Drugs, 46: 746-794 (1993).

2) Nakagawa H., Etoh T., Ishibashi Y., Higashi Y., Kawashima M., Torii H. and Harada S.: Tacrolimus ointment for atopic dermatitis. Lancet, 344: 883 (1994).

3) Iwasaki K., Kawamura A., Teramura Y., Hata T., Ninomiya S. and Esumi Y.: Absorption, distribution, and excretion of ${ }^{14} \mathrm{C}$-labeled tacrolimus (FK506) ointment after a single dermal application to the rat. Xenobio Metabol and Dispos, 14: 1-10 (1999).

4) Kawamura A., Iwasaki K., Fujita E., Teramura Y. and Hata T.: Pharmacokinetics of tacrolimus (FK506) ointment after a single dermal application to the rat. Xenobiotic Metabolism and Disposition, 14: 11-15 (1999).

5) Iwasaki K., Shiraga T., Nagase K., Hirano K., Nozaki K. and Noda K.: Pharmacokinetic study of FK506 in the rat. Transplantation Proceeding, 23: 2757-2759 (1991).

6) Iwasaki K., Shiraga T., Matsuda H., Teramura Y., Kawamura A., Hata T., Ninomiya S. and Esumi Y.: Absorption, distribution, metabolism and excretion of tacrolimus (FK506) in the rat. Xenobiotic Metabolism and Disposition, 13: 259-265 (1998).

7) Iwasaki K., Matsuda H., Shiraga T., Kawamura A., Miyazaki Y., Teramura Y., Tozuka Z. and Hata T.: Comparison of tacrolimus (FK506) levels determined by three different methods in the rat blood. Xenobiotic Metabolism and Disposition, 10: 837-847 (1995).

8) Sugiura M., Iwasaki K., Noguchi H. and Kato R.: Evidence for the involvement of cytochrome $\mathrm{P}-450$ in tiaramide N-oxide reduction. Life Sciences, 15, 1433-1441 (1974).

9) Shiraga T., Iwasaki K., Nozaki K., Tamura T., Yamazoe Y., Kato R. and Takanaka A.: Isolation and characterization of four cytochrome P450 isozymes from untreated and phenobarbital-treated beagle dogs. Biological and Pharmaceutical Bulletin, 17: 22-28 (1994).

10) Lowry O. H., Rosebrough N. J., Farr A. L. and Randall R. J.: Journal of Biological Chemistry, 193: 265-275 (1951).

11) Barry B.: Skin transport, in Dermatological Formulations. Percutaneous Absorption. Marcel Dekker Inc., New York. pp95-126 (1983).

12) Hotchkiss S. A. M.: Skin as a xenobiotic metabolizing organ. Progress in Drug Metabolism, 13: 217-262 (1992).

13) Shiraga T., Matsuda H., Nagase K., Iwasaki K., Noda K., Yamazaki H., Shimada T. and Funae Y.: Metabolism of FK506, a potent immunosuppressive agent, by cytochrome P450 3A enzymes in rat, dog and human liver microsomes. Biochemical Pharmacology, 47: 727-735 (1994). 